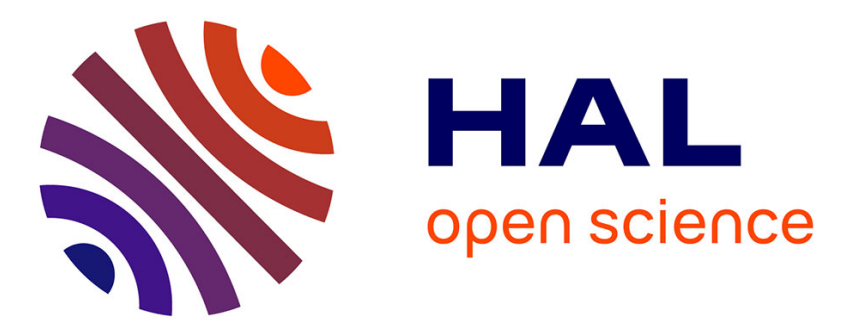

\title{
Strain rate and temperature effect on the deformation behavior of the original hadfield steel
}

\author{
E. Bayraktar, Christophe Levaillant, S. Altintas
}

\section{To cite this version:}

E. Bayraktar, Christophe Levaillant, S. Altintas. Strain rate and temperature effect on the deformation behavior of the original hadfield steel. Journal de Physique IV Proceedings, 1993, 03 (C7), pp.C7-61C7-66. 10.1051/jp4:1993706 . jpa-00251712

\section{HAL Id: jpa-00251712 https://hal.science/jpa-00251712}

Submitted on 1 Jan 1993

HAL is a multi-disciplinary open access archive for the deposit and dissemination of scientific research documents, whether they are published or not. The documents may come from teaching and research institutions in France or abroad, or from public or private research centers.
L'archive ouverte pluridisciplinaire HAL, est destinée au dépôt et à la diffusion de documents scientifiques de niveau recherche, publiés ou non, émanant des établissements d'enseignement et de recherche français ou étrangers, des laboratoires publics ou privés. 


\title{
Strain rate and temperature effect on the deformation behavior of the original hadfield steel
}

\author{
E. BAYRAKTAR, C. LEVAILLANT* and S. ALTINTAS
}

Tübitak-Marmara Research Center, Gebze-Kocaeli and Boğaziçi University, Department of Mechanical Engineering, 80815 Bebek, Istanbul, Turkey

* CEMEF, Ecole Nationale Supérieure des Mines de Paris, 06904 Sophia Antipolis, France

\begin{abstract}
In this study, the original Hadfield steel (1.2\%C and $12 \% \mathrm{Mn}$ ) is investigated under uniaxial tensile test conditions in order to evaluate the mechanical behaviour at different strain rates and temperatures. The constitutive equation of Hadfield steel is determined as a function of strain, strain rate and temperature. In an attempt to explain the mechanism of rapid strain hardening of this steel, microstructural study is also performed and the findings are related to deformation behaviour with the intent of clarifying one of the major problems of Hadfield steel.
\end{abstract}

\section{INTRODUCTION}

Hadfield steel, named after its inventor Sir Robert Hadfield, containing about $1.2 \% \mathrm{C}$ and $12 \% \mathrm{Mn}$ is extremely tough, wear, shock resistant and also very sensitive to plastic deformation [1]. It workhardens very quickly as a function of plastic deformation level. Despite very different application areas, ranging from basic machine elements to military uses of Hadfield steel since its discovery more than a century (1882) ago, its mechanism of the unusual strain hardening behaviour still remains unclear.

The mechanical properties of Hadfield steel vary with both carbon and manganese contents. The tensile strength and ductility reach a maximum at about $1.2 \% \mathrm{C}$ and then decrease steadily as the carbon content is increased. The same mechanical properties however, increase rapidly with increasing Mn content up to $12 \%$ and tend to level off $[1,2]$.

In early studies, the strain hardening in Hadfield steel was thought to be caused by strain induced transformation of $\gamma$ to $\alpha$ or $\epsilon$ martensites. But it has been shown that the austenitic phase in Hadfield steel is stable during plastic deformation at all temperatures $[2,3]$. Strain induced transformation occurs only because of decarburization or local segregation of manganese leading to unstable austenite composition.

Dastur et al. [3] suggested that the most likely cause of the rapid strain hardening in Hadfield steel is the interactions between dislocations and Mn-C couples in austenite solution, because the carbon members of C-Mn couples reorient themselves in the cores of dislocations, thereby locking the dislocation density. Thus it was concluded that dynamic strain aging is the principal cause of strain hardening in Hadfield steel and this group did not observe strain induced transformations in their studies. 
Adler et al. [4] observed that the plastic flow behaviour of Hadfield steel in uniaxial tension and compression shows $\sigma-\epsilon$ curve shape effects, indicative of transformation plasticity phenomena. They concluded that the trends in curve shape as a function of temperature correlate with the observed extent of deformation twinning. This is consistent with the softening effect of twinning as a deformation mechanism and the hardening effect of the twinned microstructure and a combination of these effects give upward curvature to the $\sigma-\epsilon$ curve.

The present study is undertaken to investigate the mechanical behaviour at different strain rates and temperatures, which does clarify the strain hardening mechanism of Hadfield steel. And finally the constitutive equation defining deformation behaviour in accordance with Hollomon is derived from the test conditions employed.

\section{EXPERIMENTAL PROCEDURE}

Tensile test specimens were prepared from Hadfield steel sheets in thickness of $1.2 \mathrm{~mm}$ by EDM in accordance with the ASTM-E8M in seven rolling directions as normal and subsize specimens. Tensile tests were performed on an Hydraulic Instron-1340 unit to study the strain rate and temperature effect on the mechanical properties and deformation behaviour of this steel. Tensile testing was carried out at initial strain rates of $0.00075,0.0075,0.075,0.30,0.37$ and $0.60 \mathrm{~s}^{-1}$ at room temperature and tensile testing at high temperatures of $100,200,300$ and $400^{\circ} \mathrm{C}$ were performed at initial strain rates; $0.083,0.33,0.83$ and $1.66 \mathrm{~s}^{-1}$. Microstructural analysis were performed by an optical microscopy. Metallographic sections of specimens tested were mechanically polished and etched for microscopic study.

\section{RESULTS AND DISCUSSION}

The stress-strain data obtained from tensile tests were analyzed by using a computer program. Mechanical properties and material flow curve parameters proposed by Hollomon were evaluated by means of this program and examined to determine the strain rate and temperature effect on the strain hardening characteristic of Hadfield steel [5].

The trends of curve shape and stress levels in stress-strain curves obtained from tension tests exhibited almost linear strain hardening behaviour and pointed to an isotropic property without necking. This behaviour defines homogeneous strain hardening characteristic of Hadfield steel, showing good agreement with the results obtained previously [4].

Figure 1 shows the change of strain hardening rate $(d \sigma / d \epsilon)$, stress and strain hardening exponent $(n)$ as a function of strain in a uniaxial tension test. As seen from this figure, strain hardening rate decreases sharply with strain showing a minimum at small strains and indicates a tendency to increase at higher strains. Strain hardening exponent varies between 0.45 to 0.95 depending on the strain level.

Mechanical properties obtained from uniaxial tensile tests at room temperature are;

Yield strength...........420 $430 \mathrm{MPa}$

Fracture strength............1350 $250 \mathrm{MPa}$

Strain until fracture....... $0.50 \pm 0.20$

Strain hardening exponent $(n)$ between 0.45 and $0.95[5,6]$.

This steel shows serration character after an amount of strain called 


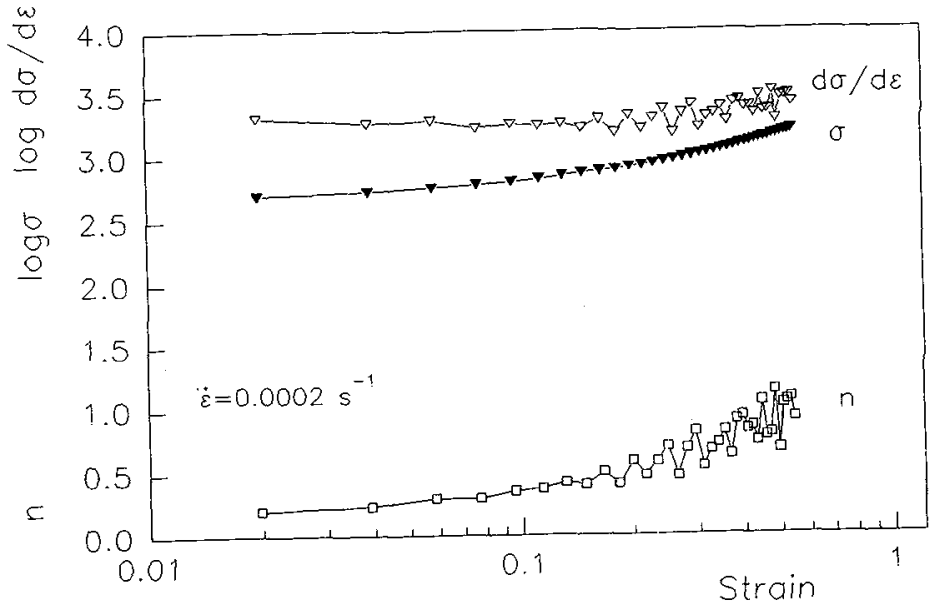

Fig. 1 - The change of stress, strain hardening rate and strain hardening exponent as a function of strain.

critical strain $\left(\epsilon_{\mathrm{c}}\right)$ which is defined as the strain at which serrations start to appear. This value was found to increase steadily from $1.6 \%$ at lower strain rates to $3 \%$ at high strain rates that were investigated [5]. Figure 2 shows stress strain curves at room temperature for different strain rates and it exhibits negative strain rate dependence of flow stress. That is to say, flow stress decreases with increasing strain rate. Figure 3 illustrates the negative temperature dependence of flow stress with an increasing slope at low temperatures. It was seen that strain hardening capacity decreases at about $300^{\circ} \mathrm{C}$ and shows blue brittleness as a result of dynamic strain aging. Neck formation occured at $400^{\circ} \mathrm{C}$.

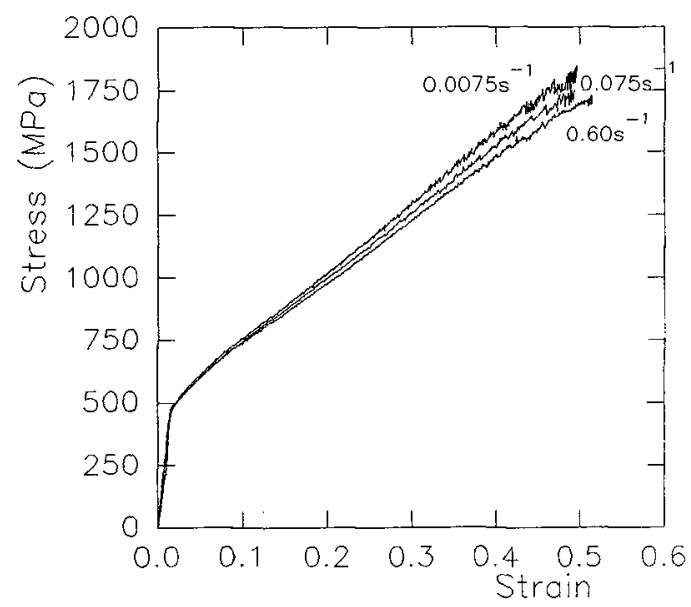

Fig. 2 - Effect of strain rate on the stress strain curve.

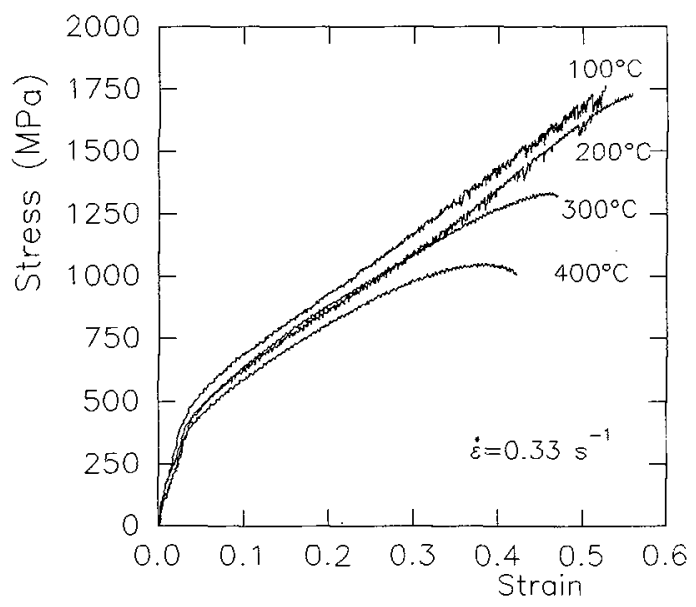

Fig. 3 - Effect of temperature on the stress strain curve. 
The strain hardening characteristic of a material is known to have often been described by a simple state equation;

$$
\sigma=\sigma(\epsilon, \dot{\epsilon}, \mathrm{T})
$$

where $\epsilon, \dot{\epsilon}, T$ are the strain, strain rate and temperature, respectively. If strain rate and temperature are assumed constant, the plastic state equation can be approximated by the constitutive equations to describe the stress-strain relationships in the plastic region of the curve [7]. Strain rate and temperature dependence of flow curve parameters in Hollomon equation can be described as;

$$
\sigma=\mathrm{K}(\dot{\epsilon}, \mathrm{T}) \epsilon^{\mathrm{n}(\dot{\varepsilon}, \mathrm{T})}
$$

where $K$ and $n$ are strength coefficient and strain hardening exponent, respectively. This power law was chosen for the sake of simplicity. For this reason, strain rate dependent constitutive equation can be defined by writing the strength coefficient (K) and strain hardening exponent $(n)$ as a function of strain rate.

$$
\begin{aligned}
& \mathrm{K}=\mathrm{K}_{1} \dot{\epsilon}^{\mathrm{a}} \\
& \mathrm{n}=\mathrm{n}_{1} \dot{\epsilon}^{\mathrm{b}}
\end{aligned}
$$

The parameters in equations (3) and (4) were determined by fitting the experimental flow curves [5]. A strain rate dependent constitutive equation valid at room temperature with an accuracy of $1 \%$ on all initial strain rate ranges studied, is obtained as follows;

$$
\sigma=2302 \dot{\epsilon}^{-0.009} \epsilon^{0454 \dot{\epsilon}^{-0.012}}
$$

In addition, temperature dependent constitutive equation can also be obtained by finding the temperature dependency of constants in equations (3) and (4) in accordance with Zener-Hollomon parameter [8]. Among these constants $a$ and $b$ are found to be weakly affected from temperature and their average values are used in the equation. Other constants, $k_{1}$ and $n_{1}$ are found to be strongly dependent on temperature and they are:

$$
\begin{aligned}
& K_{1}=1161 e^{237 / T} \\
& n_{1}=0.257 e^{194 / T}
\end{aligned}
$$

Finally strain rate and temperature dependent constitutive equation for Hadfield steel can be written as follows:

$$
\sigma=1161 \mathrm{e}^{237 / T} \dot{\epsilon}^{0.01} \epsilon^{0.257 \mathrm{e}^{194 / T} \dot{\epsilon}^{0.01}}
$$

The evolution of deformation twin density with plastic strain is shown by the optical micrographs of specimens in Figure 4. It was seen that the amount of twin density increases with plastic strain progressively and a strong relationship exists between strain and twin formation accounting for strain hardening. It was observed that there is only a little difference between twin densities of the micrographs of fractured specimens at the deformation temperature ranges investigated. It was observed that the microstructural change with strain level is more significant than that with temperature over the range studied. No carbide precipitations occured at the grain boundaries, in consistency with previous studies $[3,4]$.

The microhardness values on each region, i.e. twinned, non-twinned grains and grain boundary, of the deformed specimens at room temperature were 
plotted as a function of strain in Figure 5. This figure shows that there was no significant difference between the hardness values of these regions at low strains (up to 0.3 ), but the hardness values of twinned

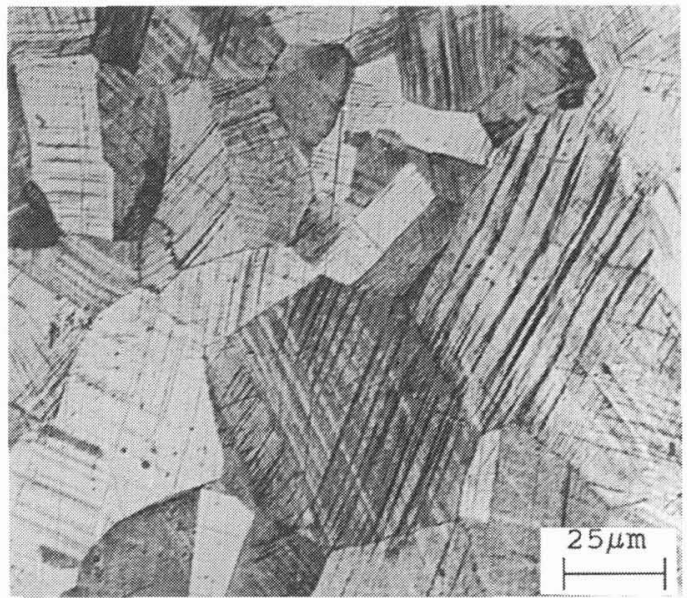

(a)

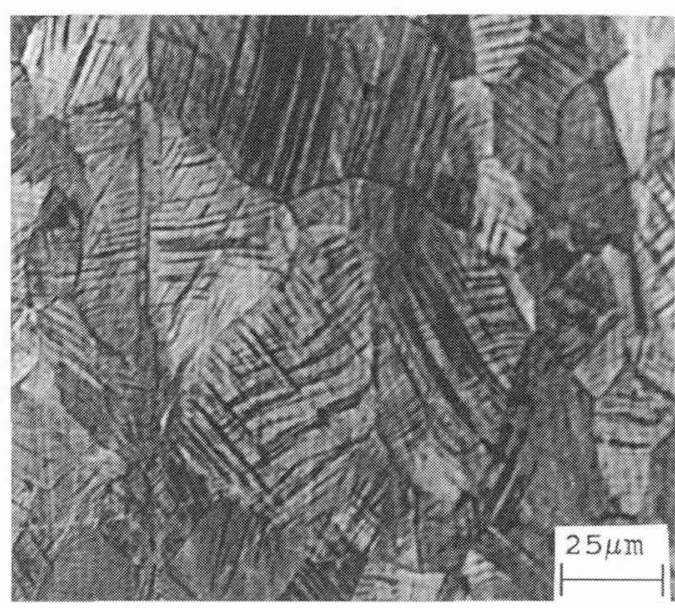

(b)

Fig. 4 - Microstructures of Hadfield steel showing deformation twins after a) 0.15 and b) 0.75 strain at room temperature.

grains were much higher than that of the other regions at high strain levels and at room temperature. This indicates that Hadfield steel shows a remarkably high strain hardening behavior associated with twin formation at high strain levels and at room temperature. It was found that the hardness value at the fracture side is very high and about 650 HVN. However hardness from fracture surface remained usually constant showing homogeneous strain hardening characteristic of this steel. This is supported by the fact that the strain hardening exponent in this system varies between 0.45 to 0.95 depending on the strain level [6].

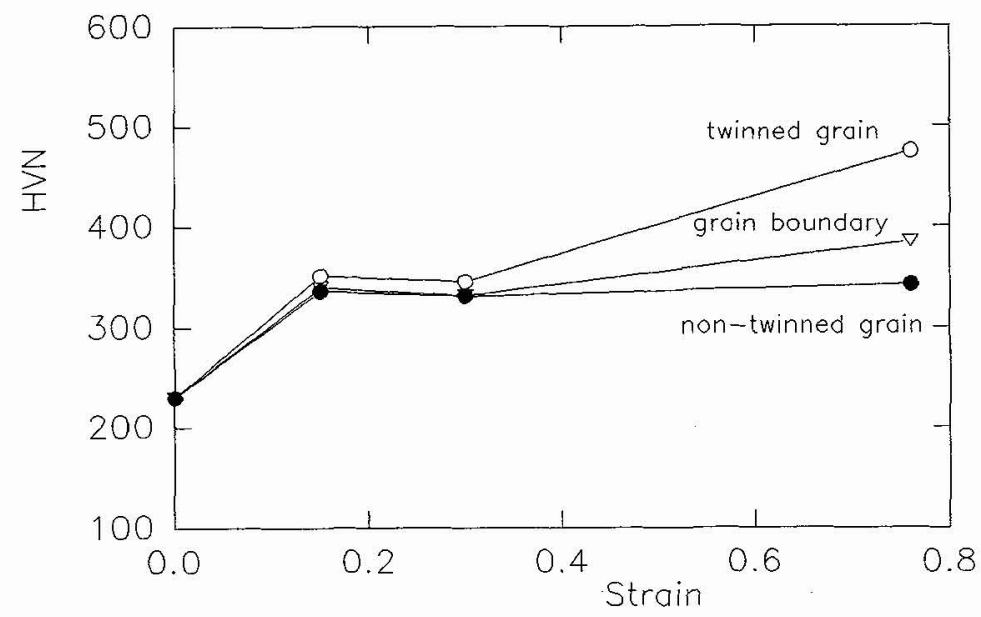

Fig. 5 - Variation of microhardness with strain at room temperature. 


\section{CONCLUSIONS}

Hadfield steel shows an isotropic property and its strain hardening behaviour is linear at room temperature. Strain hardening exponent (n) varies between 0.45 to 0.95 depending on the strain level.

Strain hardening capacity decreases at about $300^{\circ} \mathrm{C}$ and shows blue brittleness and neck formation at $400^{\circ} \mathrm{C}$.

There is a strong relationship between hardness value and the extent of deformation twins causing strain hardening. Hardness distribution showed homogeneous strain hardening characteristic of this steel.

From the microhardness measurements and microstructural observations, it can be concluded that deformation twins have a strong effect on the strain hardening mechanism in Hadfield steel.

\section{Acknowledgements}

This work was supported by CEMEF-Ecole des Mines de Paris, Sophia Antipolis/France. The assistance of Mrs. Susan JACOMET with photographs taken from optical microscopy and the assistance of Mr. Gillbert Fiorucci with experiments in Instron is gratefully appreciated.

\section{REFERENCES}

[1]. Metals Handbook 9th. Ed. (1989) p.568.

[2]. DOEPKEN H.C., J.of Metals 2 (1952) 167.

[3]. DASTUR Y.N., and LESLIE W.C., Met. Trans. 12A (1981) 749.

[4]. ADLER P.H., OLSON G.B. and OWEN W.S., Met. Trans. 17 (1986) 1725.

[5]. BAYRAKTAR E., LEVAILLANT C. and ALTINTAS S., Final Report, CEMEFEcole des Mines de Paris, Sophia Antipolis-France (1992).

[6]. ALTINTAŞ S., SAVAŞ M.A. and BAYRAKTAR E., Final Report, Boğaziçi University Istanbul-TURKEY (1990).

[7]. MISHRA N.S., MISHRA S., and RAMASWAMY V., Met. Trans. 20A (1989) 2819 .

[8]. DIETER G.E., Mechanical Metallurgy, McGraw-Hill, (1986) p.307. 